\title{
Positioning of Micro Particles Inside Droplets Using Acoustophoresis
}

\author{
Amir Shamloo ${ }^{1}$, Alireza Sahhaf ${ }^{1}$, and Rohollah Nasiri ${ }^{1}$ \\ ${ }^{1}$ Affiliation not available
}

September 11, 2020

\begin{abstract}
Acoustophoresis is a promising method in micro and nanotechnology attracting particular attentions as an efficient particle handling method. Droplet-based microfluidics has emerged as a valuable tool for miniaturization of biological reactions. This study numerically investigates a method of enriching the concentration of particles inside a droplet. The advantage of this method is that it proposes a non-contact solution to handle biological particles such as RBCs, CTCs and proteins. The finite volume method (FVM) was used as a CFD tool to model and simulate the problem. Particles were simulated using the discrete phase model (DPM). The numerically acquired results were compared with experimental data and were validated. Water droplet sizes were increased with an increase in the ratio of water to oil flow rate. Furthermore, some geometrical aspects were investigated in this work. An optimized microchip geometry, which resulted in an optimal enrichment of particles, was proposed by comparing different geometries.
\end{abstract}

\section{Hosted file}

SAHAF-NASIRI2 .pdf available at https://authorea.com/users/358412/articles/480587-positioningof-micro-particles-inside-droplets-using-acoustophoresis 